\title{
Promote Technology Self-efficacy via a SCORM-Based e-Learning Approach
}

\author{
Xin Bai
}

\begin{abstract}
The purpose of this study is to explore the relationship between undergraduate students' perceptions of their basic computer literacy skills (self-efficacy) and their attitudes toward the hybrid learning experiences after completing a 15-week SCORM-based hybrid-learning course. Two hundred and forty-six students from a historically black senior college participated in the study. Students completed an anonymous self-assessment survey at the end of the semester. The results show that students with higher self-efficacy beliefs are more likely to report positive learning experiences, including learning pace control, time management, and content understanding. However, students with lower self-efficacy beliefs are more likely to respond that the topics are difficult to follow and time online is hard to control, and they prefer a face-to-face rather than online session. Implications of these findings and the strengths and limitations of such an elearning framework are discussed to inform future research on identifying effective hybrid-learning tools and pedagogies in order to increase self-efficacy for improved motivation and academic performance.
\end{abstract}

Index Terms-SCORM, elearning, efficacy, instructional design, motivation, hybrid learning, cognition.

\section{INTRODUCTION}

An individual's perceived ability, or self-efficacy, to adopt computer technology successfully has been found to be a major factor affecting his or her willingness to accept new technology [1], [2]. Research showed that those with high self-efficacy performed better academically than those with low self-efficacy. Also difference in self-efficacy correlates to fundamentally different worldviews. People with high self-efficacy generally believe that they are in control of their own lives, that their own actions and decisions shape their lives, while people with low self-efficacy may see their lives as outside their control [3]. Compeau, Higgins, and Huff [4] tested the influence of computer self-efficacy beliefs, outcome expectations, affect, and anxiety on computer use, and found that computer self-efficacy beliefs had a significantly positive influence on computer use.

Although hybrid-learning tools are developing rapidly, making education more accessible, affordable, and equitable, digital gap still exists where students from disadvantaged socioeconomic background have less access to computers and the Internet, thus less experience with the current technological tools. Low self-efficacy on computer literacy

Manuscript received March 10, 2016; revised May 15, 2016. This work was supported in part by the Professional Staff Congress Grant at the City Univ. of New York.

Xin Bai is with York College of the City Univ. of New York, 94-20 Guy Brewer Blvd., Jamaica, NY, 11451, USA (e-mail: xbai @york.cuny.edu). may affect how students accept and use computers limited due to fear of computers, confidence and ability, resistance to new technology, perceived difficulty of use, not understanding the importance of technology, and lack of motivation to adopt a new technology [5]. More research is needed to identify effective hybrid-learning tools and pedagogies to increase students' self-efficacy for improved motivation and academic performance.

We ask the following research questions to address the issues above.

Do students have high self-efficacy after a semester of learning the basic computer literacy skills via our hybrid-learning framework?

Do students' self-efficacy beliefs correlate with their perceptions of the hybrid-learning experiences?

What are factors that affect self-efficacy during the hybrid learning experiences?

\section{BACKGROUND}

\section{A. Self-efficacy}

Self-efficacy, the belief that one has the ability to perform a particular action, is an important construct of the Social Cognitive Theory [6], in which Bandura suggests the formation of self-efficacy beliefs is based primarily on reflection and interpretation of past performance. The perceived self-efficacy plays an important role in affecting motivation and behavior. For instance, students' academic performances may differ markedly when they have similar ability with different self-efficacy beliefs. One explanation is these self-beliefs may play a mediational role in relation to cognitive engagement and that enhancing them might lead to increased use of cognitive strategies that, in turn, lead to improve performance [7]. The self-efficacy theory has been used as an important indicator for predicting and improving work performance and behavior by other researchers [8]-[11]). It is important that college students develop positive self-efficacy beliefs in computer literacy capacities to become confident and competent professionals in the digital world.

\section{B. Hybrid Learning}

Computer literacy has become the basic requirement in almost all the professions. Adult learners are autonomous, self-directed, goal-oriented, and relevancy-oriented [12]. Students can now choose a campus that can provide excellent blended learning curricula with minimal geographical restraints. This calls for further exploration of effective pedagogies and hybrid learning design strategies that harness the affordance of information technologies. 
Educators should act as facilitators that motivate adult learners to engage in meaningful learning activities that lead to knowledge retention and learning transfer in the real world. Hybrid learning proves to be an effective learning environment that enables adult learners to combine face-to-face learning and online learning. Chickering and Gamson [13] state allocating realistic amounts of time means effective learning for students and effective teaching for faculty. The interest of hybrid learning is increasing rapidly [14]-[16]. Hybrid learning contents also grow exponentially with lessons and good practices documented [17], [18]. We need a systematic approach that integrates these good practices and effective approaches so that hybrid-learning modules can be shared and reused among instructors and adult learners. We also need to make sure such hybrid-learning modules will create positive user experiences that increase students' self-efficacy beliefs in the target subject.

\section{SCORM-Based System Design for Hybrid Learning}

SCORM (Shareable Content Object Reference Model) is an elearning standard specification initiated by the Advanced Distributed Learning (ADL). It is sponsored by Department of Defense of the U.S, which mandated that all its elearning purchases should be SCORM-compliant (DOD, 2001). Among SCORM goals are the ability to enable interoperability, accessibility and reusability of web-based learning content for industry, government, and academia. It aims to achieve the ideal of learning anytime anywhere through enabling any SCORM-conformant elearning content, developed with any authoring tool, to be distributed to any learner, from any platform, by any SCORM-conformant LMS Today, most major LMSs and educational software vendors comply with this standard for creating and deploying elearning.

A SCORM-compliant elearning module can track, among other things, the time each student spends in the module, which area he or she is having trouble in and, with that information, dictate what modules should be provided next. This individualized approach allows for optimal self-paced learning. Also, elearning modules have the potential to be utilized across a variety of curriculum. For example, the college's research librarian could create a chapter built from elearning modules that teaches and evaluates students' abilities to critically examine web resources. This information literacy chapter could be used in a variety of courses ensuring students are prepared for online research.

\section{REUSABLE AND SHARABLE SCORM-BASED FRAMEWORK DESIGN}

In our study, we developed SCORM-based scalable, shareable, and sustainable e-learning modules that could be assembled as chapters and distributed through any web-enabled device. The e-learning modules combine both content and assessment and are presented in an ordered fashion that allows a student to practice and drill as they gain knowledge. The final product is an electronic textbook alternative unlike the current trend for e-textbooks, which are simply digital copies of traditional textbooks. The goal of the research is to help students develop positive self-efficacy beliefs in their computer literacy capacity through positive experiences with hybrid elearning. Two college assistants helped design and develop elearning modules with a total workload of about 15 hours a week. They were both from the Teacher Education department with limited technical background. They used LessonBuilder as an authoring tool to assemble modules into chapters - one for each week. Instructional strategies were considered throughout the design process. SCORM does not regulate which instructional strategies should be used and how. We implemented instructional strategies through designing interactive components (e.g., flash card games, cross-word puzzles), providing just-in-time feedback (e.g., quizzes), promoting collaboration (e.g., online discussion through LMS), or encouraging social networking (e.g., peer support through blogging).

We did an initial training with the two instructors who taught the course in hybrid format for the first time. They had taught the same course in face-to-face format in earlier semesters. They felt the flow of the course structure was clear and the design of each elearning module was well thought-out and reasonable. They were trained on how to manage the content in our LMS (Blackboard), including user activities, learning attempts, and duration of learning, misconceptions. They were solicited for feedback on usability throughout the processes.

Once completed, the weekly modules were posted to BlackBoard, each of which was self-contained with lecture notes, readings, activities (e.g., games, puzzles, etc.), and assignments. These modules were constantly revised to fit the instructional needs throughout the semester (Fig. 1).

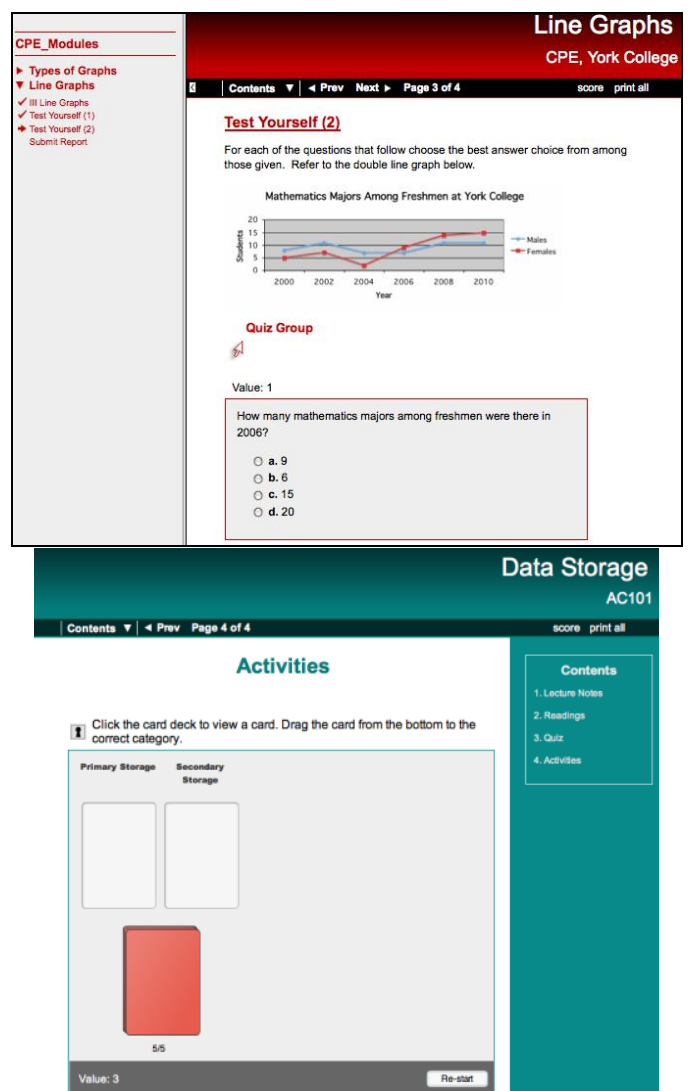

Fig. 1. A SCORM-based prototype for CPE workshop and a computer literacy course. 
The basic components (SCOs) were packaged together to make an elearning chapter.

\section{METHOD}

\section{A. Setting}

This study was collected from nine computer literacy course sessions at a historically black senior college over three semesters. The 15-week course was required for students in nursing, social work, business, and teacher education. One of the instructors is the researcher in this study Each face-to-face session was 90 minutes in a computer lab where each student has computer access. Seven sessions were online and 8 sessions were face-to-face.

\section{B. Participants}

246 undergraduates, most of them freshmen, participated in the study. They took a computer literacy course and completed an anonymous online survey at the end of the semester. 230 students gave us consent to use their survey responses.

\section{Research Design and Instruments}

This study utilizes anonymous online survey at the end of the semester. The quantitative data includes 5-scale Likert scale questions ranging from Strong Agree to Strongly Disagree. The questions about students' perception of their basic computer literacy skills include history of computers, input and output, data storage, social networking, creating cover letter and resume, Power Point, and Excel. These topics were covered in the hybrid-learning course via e-learning modules. Eight Likert scale questions quantify the attitudes of participants towards their learning experiences. Half of the statements indicated a positive experience with the case studies (e.g., "The weekly modules were helpful in understanding the course content.") and half of the statements indicated a negative experience (e.g., "The weekly modules were difficult to follow.").

\section{RESULTS}

\section{A. Students'Self-efficacy Beliefs about Their Computer Literacy Skills}

Table I below depicts students' perception of their computer skills $(N=230) .72-80 \%$ students expressed positive feeling about their basic computer skills, while 6-10\% students expressed negative feeling about what they know about the target computer skills. This shows students were overwhelmingly more positive about their learning outcome after the hybrid learning experiences.

\section{B. Students' Attitudes about Their Hybrid Learning Experiences}

The majority of the respondents (79\%) from the 9 course sessions believed that they were able to control the pace of their own learning and the online assignments were helpful in understanding the course content $(78 \%)$. This is consistent with another question in which only $5 \%$ respondents indicated the online materials were difficult to follow. The overall student attitude towards the hybrid course is positive. $81 \%$ of the respondents would recommend taking hybrid courses to a friend. 5\% respondents wouldn't do so. Although still positive, relatively less respondents (44\%) said they were able to share ideas on a regular basis, but $30 \%$ thought they were not able to share ideas with peers. Also, most respondents (80\%) indicated the connection between class and online sessions was clear and they preferred to spend time online than face-to-face (Fig. 2 \& Fig 3).

TABLE I: QUESTIONS ANSWERS FROM THE SURVEY $(N=230)$

I feel I know more about the following concepts after taking this course:

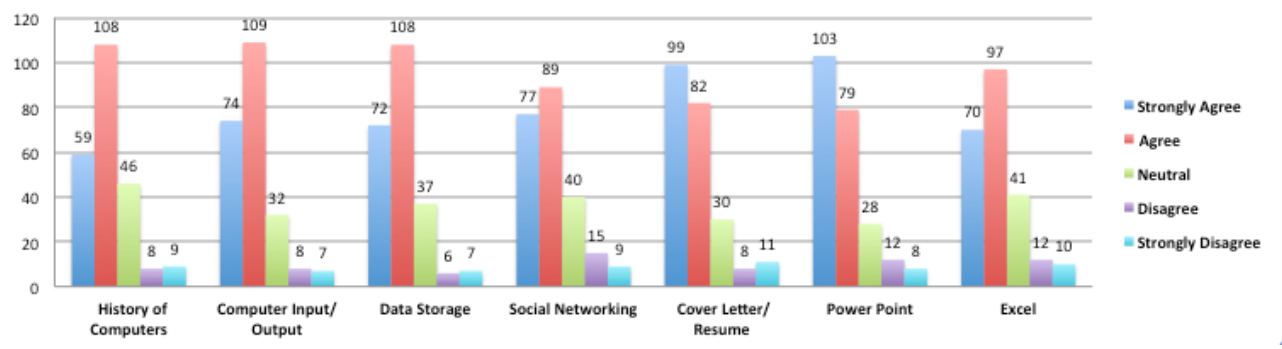

\begin{tabular}{|c|c|c|c|c|c|}
\hline & Strongly Agree & Agree & Neutral & Disagree & Strongly Disagree \\
\hline = The weekly modules were difficult to follow. & $39 \%$ & $40 \%$ & $17 \%$ & $3 \%$ & $2 \%$ \\
\hline $\begin{array}{l}\text { I I was able to control the pace of my own } \\
\text { learning. }\end{array}$ & $39 \%$ & $40 \%$ & $17 \%$ & $3 \%$ & $2 \%$ \\
\hline $\begin{array}{l}\text { = I would recommend taking hybrid courses to a } \\
\text { friend. }\end{array}$ & $51 \%$ & $30 \%$ & $13 \%$ & $2 \%$ & $3 \%$ \\
\hline $\begin{array}{l}\text { = I was unable to share ideas with other students } \\
\text { on a regular basis. }\end{array}$ & $12 \%$ & $18 \%$ & $27 \%$ & $23 \%$ & $21 \%$ \\
\hline $\begin{array}{l}\text { I I didn't have any difficulty managing my time } \\
\text { for the online part of the course. }\end{array}$ & $43 \%$ & $36 \%$ & $14 \%$ & $4 \%$ & $3 \%$ \\
\hline $\begin{array}{l}=\text { The connection between what I did online and } \\
\text { in class was clear. }\end{array}$ & $43 \%$ & $37 \%$ & $14 \%$ & $4 \%$ & $2 \%$ \\
\hline $\begin{array}{l}\text { = The time I spent online would better have been } \\
\text { spent in class. }\end{array}$ & $9 \%$ & $11 \%$ & $17 \%$ & $23 \%$ & $40 \%$ \\
\hline $\begin{array}{l}\text { = The weekly modules were helpful in } \\
\text { understanding the course content. }\end{array}$ & $40 \%$ & $38 \%$ & $17 \%$ & $3 \%$ & $3 \%$ \\
\hline
\end{tabular}

Fig. 2. Students' attitudes towards their learning experience in Likert-scales. 


\begin{tabular}{|l|l|l|l|}
\hline Descriptive Statistics & Mean & Std. Deviation & N \\
\hline Questions & 3.99 & .822 & 230 \\
\hline Overall perception of computer literacy skills & 4.12 & .896 & 230 \\
\hline I was able to control the pace of my own learning. & 2.07 & 1.218 & 230 \\
\hline The weekly modules were difficult to follow. & 4.09 & .956 & 230 \\
\hline The weekly modules were helpful in understanding the course content. & & 1.330 & 230 \\
\hline The time I spent online would better have been spent in class. & 2.27 & .951 & 230 \\
\hline The connection between what I did online and in class was clear. & 4.15 & .996 & 230 \\
\hline I didn't have any difficulty managing my time for the online part of the course. & 4.11 & 1.290 & 230 \\
\hline I was unable to share ideas with other students on a regular basis. & 2.77 & .993 & 230 \\
\hline I would recommend taking hybrid courses to a friend. & 4.24 & & \\
\hline
\end{tabular}

Fig. 3. Students' attitudes towards their learning experience (descriptive).

A Pearson Chi-Square test of independence was conducted to examine the association of overall perception of computer literacy skills to different hybrid learning experiences. A significant association was found between self-efficacy on computer literacy skills with the following learning experiences:

- I was able to control the pace of my own learning: $x^{2}(1$, $n=230)=235.430, p=.000$

- The weekly modules were difficult to follow: $x^{2}(1$, $n=230$ ) $=132.934, p=.008$

- The weekly modules were helpful in understanding the course content: $x^{2}(1, n=230)=236.004, p=.000$

- The connection between what I did online and in class was clear: $x^{2}(1, n=230)=225.412, p=.000$

- I didn't have any difficulty managing my time for the online part of the course: $x^{2}(1, n=230)=182.905, p$ $=.000$

- I would recommend taking hybrid courses to a friend: $x^{2}$ $(1, n=230)=184.683, p=.000$

No significant association was found between the overall perceptions of computer literacy skills with the following experiences:

- The time I spent online would better have been spent in class: $x^{2}(1, n=230)=109.792, p=.159$

- I was unable to share ideas with other students on a regular basis: $x^{2}(1, n=230)=103.434, p=.284$

\section{DISCUSSION}

Currently, we are building the elearning modules on top of an existing LMS, BlackBoard, which may be down for system upgrades or maintenance. As our SCORM-compliant elearning modules are self-contained, each learning module can be burned to $\mathrm{CD}$ or downloaded from the web and run from a user's computer as an application. In the near future, we plan to host elearning modules via the cloud, on remote servers. Therefore, instructors do not need to maintain a server, database, or hardware, which is offered and maintained by commercial companies as utility services (e.g., Rustici's SCORM Engine service). This eliminates another system administration layer, making the constructing of learning content a simple and straightforward process.
We would like to have our future participating faculty members to have an opportunity to share their learning modules beyond their specific knowledge domain. For instance, an instructor building Geology elearning modules could adopt SCOs on Chemistry foundations. Students will benefit the most by receiving instruction from experts across disciplines using the shared and reassembled elearning modules. The authoring tool, LessonBuilder, allows us to load lessons from the local computer to make a new learning package. We can achieve learning module sharing through hosting packaged lessons from a network drive.

Ownership and intellectual property issues could prove to be an impediment to adoption broadly by professors. The creator of each SCO would be its owner and would have the option of not including it in the knowledge base. Also, instructors could decide to create SCOs and make them available only in limited circumstances. We hope to encourage an OpenCourseWare model that will be under some form of a Creative Commons License. We believe instructors will see advantages to having their SCOs adopted in a variety of elearning modules as they receive recognition. This recognition can lead to publication in discipline specific publications or Scholarship of Teaching and Learning publication.

Although the SCORM standard has been required in government and industry for elearning content interoperability, academia has been slow to follow their lead. This is partially due to the lack of resources, expertise, and technical support to promote the elearning standardization effort. For instance, Blackboard is a big LMS player in K-16, but its current support of SCORM is still limited. One of the biggest promises of the latest version of SCORM standard, SCORM 2004, is its sequencing feature that tailors instructions to individual needs. But our institution's current Blackboard license, Version 8, which we used, did not support SCORM 2004 as they claimed. There are occasional system glitches running the older version of SCORM 1.2 as well.

We have been in direct contact with the Blackboard's developers of their SCORM plug-in. They communicated that there is a lack of motivation to make Blackboard fully SCORM-conformant, as few universities have allocated resources to develop SCORM-based elearning contents. 
Blackboard's stance seems emblematic of academia's current level of interest in SCORM.

But this may change over time given SCORM's penetration in other markets. Fletcher et al. [19] estimated that more than 6 million SCORM learning objects were available globally. It's important to help educators secure the benefits being realized in business by enabling them to locate and access ADL objects already available in industry and government repositories [20]. This is the area that needs much research in the near future.

Based upon the results of this study, we next pose to answer the following questions:

Do students have high self-efficacy after a semester of learning the basic computer literacy skills via our hybrid-learning framework? Do students' self-efficacy beliefs correlate with their perceptions of the hybrid-learning experiences?

The results show that students with higher self-efficacy beliefs are more likely to report positive learning experiences, including learning pace control, time management, or content understanding. On the other hand, students with lower self-efficacy beliefs are more likely to state that the topics are difficult to follow and the time online is harder to control. They are more likely to prefer face-to-face rather than online learning.

\section{A. Is Such a System Readily Scalable?}

New technologies emerge on daily basis. We should try to avoid developing a prototype that may soon become obsolete. Web 2.0 provides web-based applications and services through cloud computing. These applications can interface with each other. A SCORM-based elearning approach allows non-programmer to assemble re-usable elearning modules and embed them in Web2.0 environments for collaboration and knowledge sharing. For instance, a chapter on the Internet for Education can also be adopted in a Teacher Education course, providing opportunities for students to read the materials, practice, and communicate with others. Such systems can expand as the scope of the knowledge repository increases. As contents and instructional strategies are separated, such a system can scale up to fit to different instructional and learning needs.

\section{B. What Tools do Teachers Need to Develop Open access e-Learning Modules?}

The elearning content developed should be interoperable across platforms through flexible delivery options. We created a generic elearning development process based upon widely adopted web authoring tools such as Dreamweaver, MS. Word, FrontPage, MS Visio Studio, and SoftChalk. For starters, we developed some elearning module templates for faculty. These include the basic components in a chapterquizzes, readings, lecture notes, interactive games. It's the first step to help teachers rapidly develop contents that could generate more thoughtful insights on such issues as human-computer interaction and adaptive elearning.

\section{How Can Informal Learning Be Encouraged through an Open access Framework?}

As students spend more time online socializing, exploring web pages, educators need to find a more effective way to interact online as a learning facilitator. Through the affordance of Web 2.0 technologies, teachers can promote informal learning by authoring SCORM-based elearning contents, designing activities, and facilitating social interactions in a pervasive way. Based upon the positive summative survey from students and informal feedback from instructors, we are encouraged to continue our effort towards promoting learning anytime anywhere through such an open access framework.

\section{CONCLUSION}

Our practical elearning approach via a common elearning standard allows the ever-growing knowledge base to be scalable and sharable. The results show that students with higher self-efficacy beliefs are more likely to report positive learning experiences, including learning pace control, time management, and content understanding. And students with lower self-efficacy beliefs are more likely to respond that the topics are difficult to follow and time online is hard to control, and they prefer a face-to-face rather than online session. Implications of these findings and the strengths and limitations of such an elearning framework will help us identify effective hybrid-learning tools and pedagogies in order to increase self-efficacy for improved motivation and academic performance.

\section{REFERENCES}

[1] T. Hill, N. D. Smith, and M. F. Mann, "Role of efficacy expectations in predicting the decision to use advanced technologies: The case of computers," J. Appl. Psvchol, vol. 72, pp. 307-313, 1987.

[2] D. Leonard-Barton and W. A. Kraus, "Implementing new technology," Harvard Bus. Rev., vol. 63, November-December, pp. 102-110, 1985.

[3] L. Sherry, "Diffusion of the internet within a graduate school of education university of Colorado," Dissertation, 1998.

[4] D. Compeau, C. A. Higgins, and S. Huff, "Social cognitive theory and individual reactions to computing technology: A longitudinal study," MIS Quarterly, vol. 23, pp. 145-158, 1999

[5] S. B. Lucas, "Who am I? The influence of teacher beliefs on the incorporation of IT by higher education faculty," Dissertation Abstracts International, (UMI No.3193807), 2005.

[6] A. Bandura, Self-efficacy: The Exercise of Control, New York: Freeman, 1997.

[7] P. R. Pintrich and E. D. Groot, "Motivational and self-regulated learning components of classroom academic performance," Journal of Educational Psychology, vol. 82, no. 1, pp. 33-50, 1990.

[8] M. E. Gist, "Self-efficacy: A theoretical analysis of its determinants and malleability," Acad. Mgmt Rev., vol. 17, pp. 183-211, 1992.

[9] A. Bandura, "Self-efficacy mechanism in human agency," Am. Psychol., vol. 37, pp. 122-147, 1982.

[10] A. Bandura, "The explanatory and predictive scope of self-efficacy theory," J. Soc. Clin. Psychol., vol. 4, pp. 359-373, 1986.

[11] D. Compeau and C. Higgins, "A social cognitive theory perspective on individual reactions to computing technology," in Proc. the Twelfth International Conference on Information Systems, New York, pp. 187-198, 1991.

[12] M. Knowles, The Adult Learner: The Definitive Classic in Adult Education and Human Resource Development, Houston, TX: Gulf, 1998.

[13] A. W. Chickering and Z. F. Gamson, "Seven principles for good practice in undergraduate education," Wingspread Journal, vol. 9, no. 2, 1987.

[14] K. Thorne, Blended Learning: How to Integrate Online \& Traditional Learning, London, UK: Kogan Page, 2003.

[15] T. Boyle, C. Bradley, P. Chalk, R. Jones, and R. Pickard, "Using blended learning to improve student success rates in learning to program," Journal of Educational Media, vol. 28, no. 2-3, pp. 165-178, 2003 . 
[16] K. J. Kim, C. J. Bonk, and T. Zeng, "Surveying the future of workplace e-learning: The rise of blending, interactivity, and authentic learning," eLearn Magazine, 2005.

[17] A. W. Chickering and S. C. Ehrmann. (2011). Implementing the seven principles: Technology as lever. [Online]. Available: http://www.aahe.org/technology/ehrmann.htm

[18] A. L. Ellis, E. D. Wagner, and W. R. Longmire, Managing Web-Based Training: How to Keep Your Program on Track and Make It Successful, Arlington, VA: ASTD Press, 1999.

[19] J. D. Fletcher, S. Tobias, and R. A. Wisher, "Learning anytime, anywhere: Advanced distributed learning and the changing face of education," Educational Researcher, vol. 36, no. 2, pp. 96-102, March 2007.

[20] J. Roschelle and J. Kaput, "Educational software architecture and systemic impact: The promise of component software," Journal of Educational Computing Research, vol. 14, no. 3, pp. 217-228, 1996.

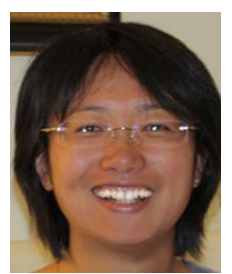

Xin Bai is an associate professor of educational technology in the Department of Teacher Education at York College, City University of New York. She earned her doctorate in instructional technology and media from teachers college at Columbia University. Her research focuses on educational games, simulations, intelligent tutoring systems, and elearning. Her work is built on the research done on cognitive science, artificial intelligence, and educational technologies. 